\title{
NUMERICAL SIMULATION OF SMOKE GENERATED BY FIRE ACCIDENTS IN TRAIN COMPARTMENT
}

\author{
Lan PENG, Cai-feng LIU, Chao LIU and You-rong LI
}

\author{
College of Power Engineering, Chongqing University, Chongqing 400044, China
}

\begin{abstract}
In this paper, the fire phenomena of compartment in YW25K train with different velocities is simulated and investigated by using Large Eddy Simulation (LES), Smagorinsky-Yoshizawa Mixed Sub-grid Scale model (SGS) and the mixture-fraction combustion model by the infinite fast chemistry kinetics. Based on the relative velocity theory, the different train running speeds are provided by the simulated wind tunnel velocities. The expanding of fire, the smoke movement and the temperature distribution in the compartment are analyzed. Some recommendations for better fireproofing design and safety management of train compartment are obtained.
\end{abstract}

Keywords: Large Eddy Simulation, Sub-grid Scale Model, Smoke Movement, Fire, Numerical simulation

\section{INTRODUCTION}

Considering the national conditions of China, the passenger train is the most important means of transport. However, if it is in the event of fire, the fire develops rapidly and spreads quickly. At the same time, the fire-induced smoke inside will fill the whole compartment in a short time. It will cause heavy casualties and economic losses due to high density of passengers in the compartment, small activity space and the high-speed of the train. Therefore, it is of great importance to study the fire smoke expanding, the flow characteristics and the temperature distributions in the train compartments, which is very significant for the train fire prevention and control.

At present, the researches of the train fire smoke are mainly focused on the natural model experiments in China. In 1999, DU Hong-bing et al. made quantitative testing for simulating temperature distribution of running trains, and qualitative analysis of the smoke flow and the spread characteristics of fire[1]. In recent years, with greatly enhanced data-processing capacity and the appearances of high-performance computers, as well as the proposed efficient numerical algorithm, the Large Eddy Simulation is being as a new field simulation method for the application of fire safety engineering[2-7].

In this paper, the LES method is used to simulate the flow of the smoke generated by the fire in the train compartment. Moreover, the movement and spread characteristic of the smoke are also analyzed.

\section{SIMULATION METHOD}

\section{1 physical and mathematical models}

The smoke movement in the compartment of the model YW25K running passenger train is calculated. Fig. 1 shows the simplified three-dimensional (3D) perspective figure of the train compartment. The structural size of the calculated area is $18.992 m \times 2.9 m \times 2.6 m(L \times W \times H)$. Source of fire is located in the middle of the compartment. The dimension is $0.5 \mathrm{~m} \times 0.5 \mathrm{~m}$, heat release rate is $1000 \mathrm{~kW}$.

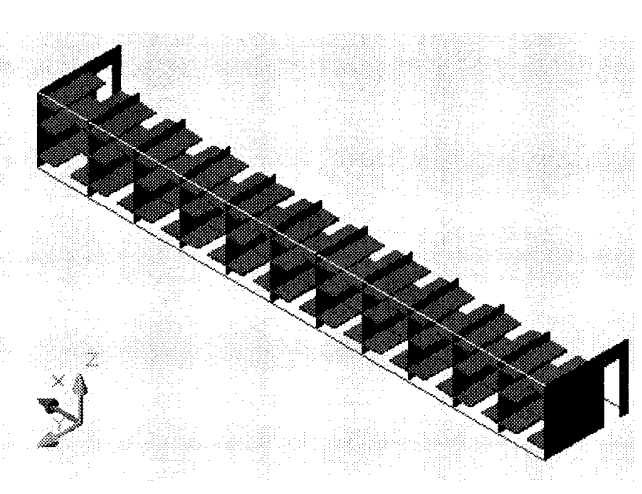

Fig.1 Three-dimensional scenograph of train compartment

According to the physical model, the smoke belongs to ideal gas which is indoor limited space and hot expansion. The Navier-Stokes conservation equations is adopted in the form of three-dimensional unsteady compressible flow to describe it.

Mass equation:

$$
\frac{\partial \rho}{\partial t}+\frac{\partial\left(\rho u_{i}\right)}{\partial x_{i}}=0
$$

Momentum equation:

$$
\frac{\partial\left(\rho u_{i}\right)}{\partial t}+\frac{\partial\left(\rho u_{i} u_{j}\right)}{\partial x_{j}}=-\frac{\partial p}{\partial x_{i}}+\frac{\partial \tau_{i j}}{\partial x_{j}}+\rho \mathrm{g}
$$

Energy equation:

$$
\begin{aligned}
& \frac{\partial(\rho h)}{\partial t}+\frac{\partial\left(\rho h u_{j}\right)}{\partial x_{j}} \\
& =\left(\frac{\partial p}{\partial t}+u_{j} \frac{\partial p}{\partial x_{j}}\right)+\frac{\partial}{\partial x_{j}}\left(k \frac{\partial T}{\partial x_{j}}\right)+\tau_{i j} \frac{\partial u_{i}}{\partial x_{j}}+Q
\end{aligned}
$$

Copyright $\odot 2009$ by the Japan Society of Mechanical Engineering 
Gas equation:

$$
p=\rho R T
$$

Here, $\rho$ is density, $g$ is acceleration due to gravity vector, $k$ is thermal conductivity, $T$ is temperature, $p$ is pressure, $h$ is enthalpy, $Q$ is the total heat release rate, $\tau_{i j}$ is viscous stress tensor which is expressed as follows:

$$
\tau_{i j}=2 \mu S_{i j}-\frac{2}{3} \mu S_{k k} \delta_{i j}
$$

Symmetric tensor in the formula (5) is expressed as follows:

$$
S_{i j}=\frac{1}{2}\left(\frac{\partial u_{i}}{\partial x_{j}}+\frac{\partial u_{j}}{\partial x_{i}}\right), \text { and } S_{k k}=\frac{\partial u_{k}}{\partial x_{k}}
$$

\section{Boundary and initial conditions}

The boundaries of all solid walls (include the walls of compartment, the ceilings and the sleeper partitions) in the train compartment are of adiabatic and no-slip condition. The doors, which are at two ends of the compartment, stay open so as to make sure that the atmospheric pressure in and out of the compartment is the same. Then, free boundary conditions are adopted in this area. At the initial moment $(t=0)$, the temperature in both the simulated wind tunnel and compartment is set at $20^{\circ} \mathrm{C}$, and the air in the calculated space is static.

\subsection{Numerical Methods}

According to the basic principal of the LES, the modified N-S equation filter cassette is introduced in this paper and the filter function stated as follows:

$G\left(x_{i}\right)=\left\{\begin{array}{l}\frac{1}{\Delta_{i}},\left|x_{i}\right| \leq \frac{\Delta_{i}}{2} \\ 0,\left|x_{i}\right| \geq \frac{\Delta_{i}}{2}\end{array}\right.$

$\Delta_{i}=(\Delta x \Delta y \Delta z)^{1 / 3}$ is filter width in the equation. All the variables in the control equation are filtered. The large-scale variables are processed by direct numerical simulation, and that of small-scale ones is completed by a unified sub-grid scale to make model assumptions. In addition, based on the methods proposed by Rehm, the flow velocity of hot flue smoke in the fire limited space, is far below the speed of sound, is in the condition of a low Mach number flow. After filtering, the control equation, which is simplified through density-weighted average method and suits the low Mach number flow, goes like this:

$$
\frac{\partial \bar{\rho}}{\partial t}+\frac{\partial\left(\bar{\rho} \tilde{u}_{j}\right)}{\partial x_{j}}=0
$$

$$
\begin{aligned}
& \frac{\partial\left(\bar{\rho} \tilde{u}_{i}\right)}{\partial t}+\frac{\partial\left(\bar{\rho} \tilde{u}_{i} \tilde{u}_{j}\right)}{\partial x_{j}} \\
& =-\frac{\partial \overline{\left(p-p_{0}\right)}}{\partial x_{j}}+\frac{\partial \tilde{\tau}_{i j}}{\partial x_{j}}+\bar{\rho} \mathrm{g}+\frac{\partial \tau_{i j}^{S G S}}{\partial x_{j}} \\
& \frac{\partial(\bar{\rho} \tilde{h})}{\partial t}+\frac{\partial\left(\bar{\rho} \tilde{u}_{j} \tilde{h}\right)}{\partial x_{j}} \\
& =\frac{d \bar{p}_{0}}{d t}+\frac{\partial}{\partial x_{j}}\left(\tilde{k} \frac{\partial \tilde{T}}{\partial x_{j}}\right)+\bar{Q}-\frac{\partial h_{t j}^{S G S}}{\partial x_{j}}
\end{aligned}
$$

$$
\bar{p}_{0}=\bar{\rho} R \tilde{T}
$$

In order to close the control equations, we use the SGS to simulate the sub-grid Reynolds stresses and turbulent heat flow:

$$
\begin{aligned}
\tau_{i j}^{S G S} & =\frac{1}{3} \tau_{k k}^{S G S} \delta_{i j}-\mu_{T} \tilde{S}_{i j} \\
h_{j}^{S G S} & =-\frac{\bar{\rho} C_{S}^{2}}{P r_{t}} \Delta^{2}|\tilde{S}| \frac{\partial \tilde{T}}{\partial x_{j}} \\
\mu_{T} & =2 \bar{\rho} C_{s}^{2} \Delta^{2}|\tilde{S}|,|\tilde{S}|=\left(2 \tilde{S}_{i j} \tilde{S}_{i j}\right)^{1 / 2}, \\
\widetilde{S}_{i j} & =\frac{1}{2}\left(\frac{\partial \tilde{u}_{i}}{\partial x_{j}}+\frac{\partial \tilde{u}_{j}}{\partial x_{i}}\right)
\end{aligned}
$$

$P r_{t}$ is the sub-grid turbulent Prandtl number in the range of $[0.2,0.9] . C_{S}$ is the Smagorinsky constant. Comparing the simulations of different $C_{S}$ values under the same condition and considering the feature that the fire smoke is driven by buoyancy in limited space, it is taken $C_{S}=0.6$ in this paper.

\subsection{Combustion Model}

Setting up of combustion sub-model is very important in fire research. It is adopted the mixed fraction as conserved scalar in this paper. According to the definition of the simplified reaction system, the mixed-fraction combustion model is taken based on ultimately fast reaction. In order to simplify the complexity of chemical combustion, a relatively simple model of fast chemical reactions is used. First, it is assumed as a complete combustion of hydrocarbon fuels, and its single-step irreversible chemical reaction is as follows:

$$
\begin{aligned}
& 4 \mathrm{C}_{n} \mathrm{H}_{m}+(4 n+m) \mathrm{O}_{2} \\
& \rightarrow 4 n \mathrm{CO}_{2}+2 \mathrm{mH}_{2} \mathrm{O}
\end{aligned}
$$

Second, assuming that the chemical reaction rate is infinitely fast, and using the Schvab-Zcldovich transform formula, we can use the control equation showed by the conserved scalar-mixed fraction $\bar{f}$ after being filtered to refer to the combustion. 


$$
\begin{aligned}
& \frac{\partial \rho \bar{f}}{\partial t}+\frac{\partial \rho \bar{u}_{j} \bar{f}}{\partial x_{j}} \\
& =\frac{\partial}{\partial x_{j}}\left(\rho D \frac{\partial \bar{f}}{\partial x_{j}}\right)+\frac{\partial W_{j}}{\partial x_{j}} \\
& W_{j}=-\rho\left(\overline{f u_{j}}-\bar{f} \bar{u}_{j}\right)=-\frac{\mu_{t}}{S c_{t}} \frac{\partial \bar{f}}{\partial t} \\
& \mu_{t}=C_{S} \bar{\rho} \Delta^{2}|S|
\end{aligned}
$$

$D$ is component diffusion coefficient, $W_{j}$ is the mass flow turbulence of the mixture fraction $f, S c_{t}$ is turbulence Schmidt number -- an experience constant which is 1.0.

In this paper, the finite difference method is used to discrete partial differential equations and all spatial derivatives are discreted by second-order center-difference scheme. The second-order explicit Runge-Kutta predictioncorrection method is adopted to solve float variables relating to the flow characteristics of smoke. The pressure solution is solved by the Poisson equation generated by the freedom divergence condition.

\section{RESULTS AND DISCUSSION}

In this paper, according to the relative velocity theory, the different wind velocities provided by the simulated wind tunnel are used to calculate smoke movement and temperature distribution when the train runs at different speeds.

\subsection{Velocity Distribution}
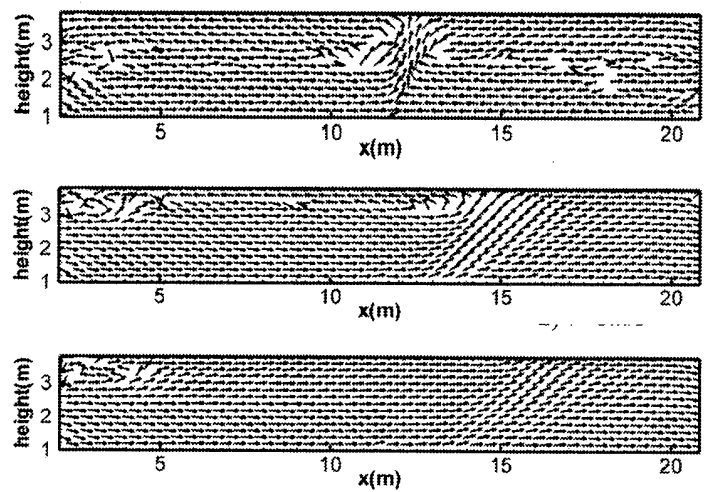

Fig.2 The time averaged velocity vector diagrams at $\mathrm{Y}=1.55 \mathrm{~m}$ ( $\mathrm{x}-\mathrm{z}$ plane $)$

Figure 2 shows that the averaged velocity distributions at the plane $(\mathrm{Y}=1.55 \mathrm{~m})$ of the central corridor along the running direction of the train when the velocity of wind tunnel is 1,3 and $5 \mathrm{~m} / \mathrm{s}$, respectively. From Fig.2, it can be found that: (1) with the increasing of the wind velocity, the inhibiting effect is strengthened on the backflow in front of compartment. When $V=5 \mathrm{~m} / \mathrm{s}$, the backflow phenomenon nearly disappears, all the smoke moves along the direction of smoke flow and spreads to the downstream; (2) with the increasing of the wind velocity, the jet flow near the ceiling in the upper part of flame zone and the air entrainment flow in lower area are all weaken. When $V=1 \mathrm{~m} / \mathrm{s}$, the air entrainment flow and the jet flow are obvious, but when $V$ increases to $5 \mathrm{~m} / \mathrm{s}$, they disappear completely; (3) when the wind velocity becomes large, the flame zone will move from central of the compartment to the back.

\subsection{Temperature Distribution}

They are analyzed the temperature distributions on the plane of the central corridor $(\mathrm{Y}=1.55 \mathrm{~m})$ and the plane of sleeper $(\mathrm{Y}=2.99 \mathrm{~m})$ along the running direction of the train with different time and different wind speeds.

\section{The Plane of the Central Corridor}
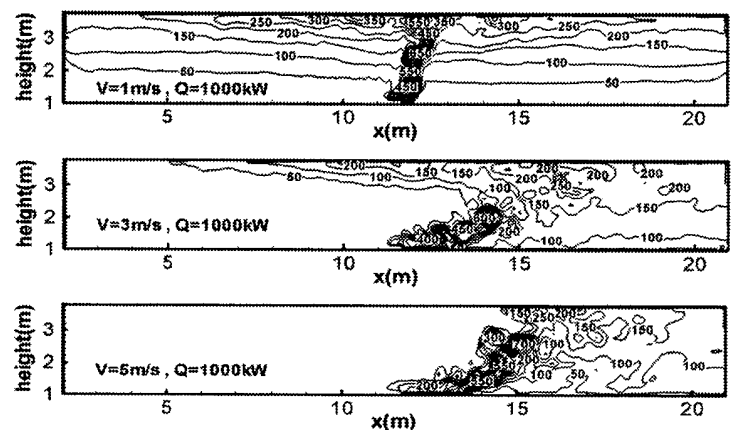

Fig.3 The isothermal distributions of smoke at $t=120 \mathrm{~s}$, $\mathrm{Y}=1.55 \mathrm{~m}$ ( $\mathrm{x}-\mathrm{z}$ plane)
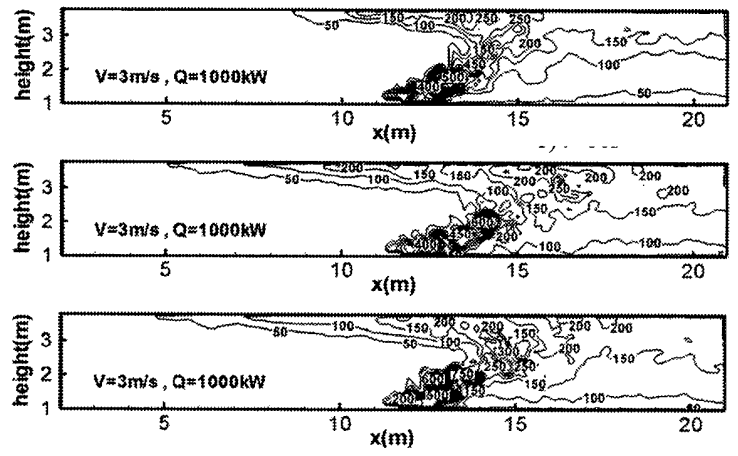

Fig.4 The isothermal distributions of smoke at $V=3 \mathrm{~m} / \mathrm{s}$, $\mathrm{Y}=1.55 \mathrm{~m}$ ( $\mathrm{x}-\mathrm{z}$ plane $)$

From Fig. 2, it can be seen that the wind velocity of wind tunnel is of great impact for the smoke flow characteristics. Then it is followed by further study on the impact of the wind velocity for the temperature distribution in the compartment at different times. The isothermal lines of different time are displayed when the velocity of wind tunnel is 1,3 and $5 \mathrm{~m} / \mathrm{s}$ at $t=120 \mathrm{~s}$ and $V=1 \mathrm{~m} / \mathrm{s}$, in the central corridor plane along the running direction of the train. It can be seen from Fig. 3, the wind velocity is also very notable for the temperature distribution in the compartment, and flame zone is the high-temperature area. With the wind velocity increasing, it will definitely take more and more impact on the smoke flow. Then it can be found that: (1) the downstream trend of hot smoke is increasingly obvious; (2) the temperature stratification phenomenon is fuzzier; (3) the angle between the center of high temperature in flame zone and vertical direction is more and more large. The trend of the flame zone adheres to the floor and spread to the back is more prevail. As it is shown in Fig.4, when the wind speed $V=3 \mathrm{~m} / \mathrm{s}$, a small amount of smoke reflux layers exist in front of the central compartment near the ceiling area. The center of flame zone has been a larger offset relatively to 
the center of the original location. Affected by the upstream coming air, majority of smoke is spread to the downstream, and then it made the $50^{\circ} \mathrm{C}$ smoke layer descend drastically. When $t=60 \mathrm{~s}$, it just is attached to the floor, meanwhile, the smoke layer with $100^{\circ} \mathrm{C}$ is down to about $1.4 \mathrm{~m}$ height. When $t=120 \mathrm{~s}$, smoke layer with $100^{\circ} \mathrm{C}$ is also attached to the ground, then the smoke layer with $150^{\circ} \mathrm{C}$ is down to about $1.4 \mathrm{~m}$ height.
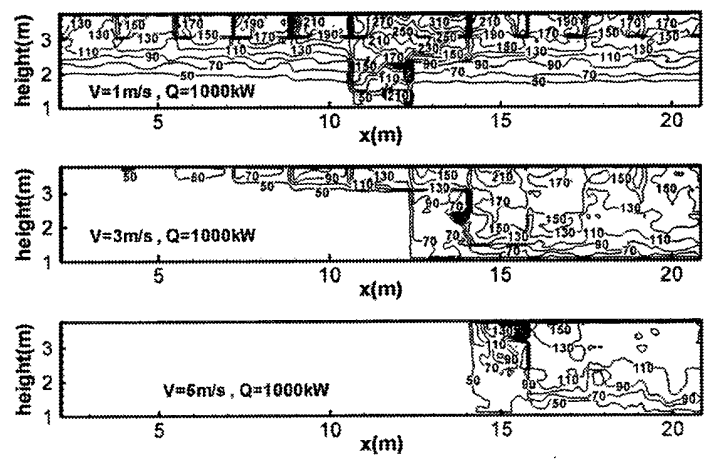

Fig. 5 The isothermal distributions of smoke at $t=180 \mathrm{~s}$, $\mathrm{Y}=2.99 \mathrm{~m}$ ( $\mathrm{x}-\mathrm{z}$ plane $)$
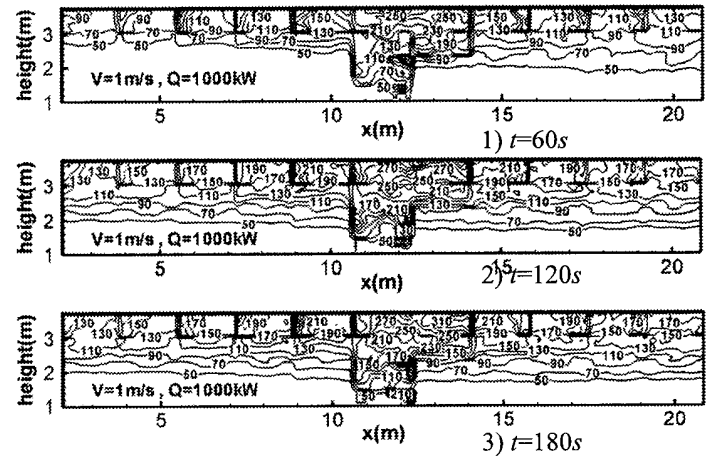

Fig.6 The isothermal distributions of smoke at $V=3 \mathrm{~m} / \mathrm{s}$, $\mathrm{Y}=2.99 \mathrm{~m}$ (x-z plane)

\section{The sleeper compartment plane}

From Fig.5 and Fig.6, it can be obtained the isothermal lines on the plane of sleeper compartment along the running direction at different time when the wind speed $V=1 \mathrm{~m} / \mathrm{s}$, and at different speed when the time $t=180 \mathrm{~s}$. Comparing to Fig.3 and Fig.4, the isothermal distribution of the sleeper compartment is quite different from the one of the train central corridor, because the clapboards of the sleeper compartment and the bed boards block off the hot smoke propagation. Then the smoke movement shows disordering, the distribution of the smoke layer is not continuous and the isothermal layer is staggeringly distributed. But the impact of wind speed on the temperature distribution shows the similar trend. With the increasing of the wind speed, flame center deviated from the beginning position. Within $60 \mathrm{~s}$, high-temperature smoke flow rapidly and fill the entire sleeper space of one or two sleeper berth rooms which away from the fire source downstream. Because the flames were spreading in the horizontal direction, in these sleeper interiors, the temperature in the lower space is significant higher than the upper temperature. With the increasing of wind velocity, the number of sleeping rooms is less for the hot smoke flows to the inside in the front of the compartment. When the wind speed comes to $V=5 \mathrm{~m} / \mathrm{s}$, the hot smoke spreads to downstream quickly, and only exists in the latter sleepers. The smoke with $50^{\circ} \mathrm{C}-110^{\circ} \mathrm{C}$ will be full of the sleeper compartment during $120 \mathrm{~s}$.

\section{CONCLUSIONS}

In this paper, the fire phenomena of compartment in YW25K train with different velocities is simulated and investigated by using Large Eddy Simulation (LES), Smagorinsky-Yoshizawa Mixed Sub-grid Scale model (SGS) and the mixture-fraction combustion model by the infinite fast chemistry kinetics. Based on the relative velocity theory, the different wind velocities are provided by the simulated wind tunnel velocities. The expanding of fire, the smoke movement and the temperature distribution in the compartment are analyzed. From the simulation results, when in the case of fire, in the limited space like passenger train compartments, the hot smoke caused by fire will be able to spread throughout. No matter in the corridor or the room, the velocity of smoke flow down is very large. About 1-2mins, the smoke could be down to about $1 \mathrm{~m}$ height above the floor. Especially, the hot smoke can be spread to all the space in the compartment within 1-2mins for the running train, in the compartment of the down wind area of fire resource. Since the hot smoke generates and spreads very fast, it will bring enormous difficulties for passengers to escape, as well as causing significant personal injury. Therefore, the timeliness of the initial stage of fire detection and effective control are very important, and it is also very significant for passengers trained to flee the scene of the fire in a short time who have been inevitable encountered when the fire occurred.

\section{REFERENCES}

1. DU Hong-bing, QI Yi-xin, YUAN Xu-zong, MA Guo-chao and Zhao Guo-tang, The Experimental Study of Running Trains Fire Smoke Characteristics and Temperature Distribution, China Railway Science, 20(3) (1999), pp.31-37. (in Chinese)

2. R.G. Rehm and H.R. Baum, The Equations of Motion for Thermally Driven, Buoyant flows. Journal of Research of the NBS, 83 (1978), pp.297-308.

3. Smagorinsky J., General Circulation Experiments with Primitive Equations-I, the Basic Experiment. Monthly Weather Rev., 91(1963), pp.99-105.

4. D.B.Spalding, Combustion and Mass Transfer, Pergamon Press, (1979).

5. ZHAO Jian-xing, Numerical Simulation of Combustion, Science Press, (2002). (in Chinese)

6. J.E. Floyd, H.R. Baum and K.B. McGrattan, A Mixture Fraction Combustion Model for Fire Simulation Using CFD. The International Conference on Engineered Fire Protection Design, Proceedings, (2001).

7. K. B. McGrattan, H. R. Baum, R. G. Rehm, A. Hamins, G. P. Forney, J. E. Floyd, S. Hostikka and K. Prasad, Fire Dynamics Simulator (Version 3) - Technical Reference Guide. NISTIR 6783, Nist Technical Report, (2002) (Ed). 